\title{
Nanostructured zinc oxide platform for cholesterol sensor
}

\author{
Pratima R. Solanki, ${ }^{a}$ Ajeet Kaushik, Anees A. Ansari, and B. D. Malhotra ${ }^{\text {) }}$ \\ Department of Science and Technology Center on Biomolecular Electronics, National Physical Laboratory, \\ Dr. K. S. Krishnan Marg, New Delhi 110012, India
}

(Received 27 November 2008; accepted 3 March 2009; published online 8 April 2009)

\begin{abstract}
Nanostructured zinc oxide (nano- $\mathrm{ZnO}$ ) film has been fabricated onto indium tin oxide (ITO) containing preferred (002) plane and $10 \mathrm{~nm}$ crystallite size using sol-gel technique for immobilization of cholesterol oxidase (ChOx). Electrochemical response of ChOx/nano-ZnO/ITO bioelectrode determined as a function of cholesterol concentration using cyclic voltammetry technique reveals improved detection range $(5-400 \mathrm{mg} / \mathrm{dl})$, low detection limit $(0.5 \mathrm{mg} / \mathrm{dl})$, fast response time $(10 \mathrm{~s})$, sensitivity $\left(0.059 \mu \mathrm{A} / \mathrm{mg} \mathrm{dl}^{-1} \mathrm{~cm}^{-2}\right)$, and low value $(0.98 \mathrm{mg} / \mathrm{dl})$ of Michaelis-Menten constant $\left(K_{m}\right)$. It is shown that nano-ZnO film provides better environment and enhanced electron transfer between ChOx and electrode. (C) 2009 American Institute of Physics.

[DOI: 10.1063/1.3111429]
\end{abstract}

Nanostructured metal oxide films such as zinc oxide $(\mathrm{ZnO})$, cerium oxide, and titanium oxide have recently attracted much attention due to their interesting optical, electrical, and molecular properties for biosensor applications. ${ }^{1-3}$ Among these, $\mathrm{ZnO}$ nanostructured film due to wide band gap $(3.37 \mathrm{eV})$, large excitation binding energy $(60 \mathrm{eV})$, high surface area, nontoxicity, good biocompatibility, chemical stability, and high electron communication feature is preferred for development of biosensors for clinical diagnostics. ${ }^{2}$ The high isoelectric point (IEP) of $\sim 9.5$ for $\mathrm{ZnO}$ is advantageous for enhanced electrostatic interaction with enzymes having low IEP.

Krishnamoorthy et $a l .^{4}$ developed surface acoustic wave biosensor to investigate characteristics of cytokine immobilized $\mathrm{ZnO}$ and $\mathrm{SiO}_{2}$ films grown onto (100) Si substrates. Wang et al. ${ }^{5}$ prepared $\mathrm{ZnO}$ nanocombs to immobilize glucose oxidase. Zhu et al. ${ }^{6}$ used $\mathrm{ZnO}$ nanoparticles to investigate electrochemistry of microperoxidase. Yan et al. ${ }^{7}$ fabricated $\mathrm{ZnO}$ based acoustic resonator as mass sensor by multitarget magnetron sputtering under optimized deposition conditions. Wei et al. $^{8}$ utilized $\mathrm{ZnO}$ nanorods array for application to glucose biosensor. Meulenkamp et al. ${ }^{9}$ prepared sol-gel based $\mathrm{ZnO}$ matrix for a mediator-free tyrosinase biosensor. The cholesterol biosensor based on rf sputtered nanoporous $\mathrm{ZnO} / \mathrm{Au}$ film ${ }^{2}$ shows high $K_{m}$, poor detection limit and is expensive. ChOx/chitosan- $\mathrm{ZnO}$ bioelectrode shows $K_{m}$ as $0.223 \mathrm{mM}$, linearity up to $300 \mathrm{mg} / \mathrm{dl}$ and shelf life of 8 weeks. $^{10}$

The sol-gel derived nanostructured metal oxide films due to better thermal stability, low cost, biocompatibility, nontoxicity, tunable porosity, low temperature processing, etc. have attracted much interest for biosensing application. ${ }^{11}$ We report results of studies relating to sol-gel derived nano- $\mathrm{ZnO}$ film deposited onto indium-tin-oxide (ITO) substrate for application to cholesterol sensor.

Zinc acetate hydrate $(1 \mathrm{~g})$ is dissolved in $20 \mathrm{ml}$ ethanol at $25{ }^{\circ} \mathrm{C}$. Then $5 \mathrm{ml}(1 M)$ solution of ammonium hydroxide is added drop wise to this solution with constant stirring for

\footnotetext{
${ }^{a}$ Electronic mail: pratimasolanki@yahoo.com.

${ }^{b)}$ Electronic mail: bansi.malhotra@gmail.com. Tel.: +91 1145609152. FAX: +91 1145609310 .
}

$1 \mathrm{~h}$ at $25^{\circ} \mathrm{C}$ to maintain $p \mathrm{H} 10$. A white precipitate of $\mathrm{Zn}(\mathrm{OH})_{2}$ obtained is washed several times with de-ionized water until neutral $p \mathrm{H}$ is reached. Subsequently, dilute $\mathrm{HNO}_{3}$ $(1 M)$ is added to precipitate at $60{ }^{\circ} \mathrm{C}$ to obtain a solution of $p \mathrm{H}$ 1. The resulting sol is used to fabricate thin film on ITO coated glass plate via dip coating technique and allowed to dry at $500{ }^{\circ} \mathrm{C}$. $10 \mu \mathrm{l}$ of $\mathrm{ChOx}[1.0 \mathrm{mg} / \mathrm{ml}$, in phosphate buffer (PB), $50 \mathrm{mM}, p \mathrm{H} \mathrm{7.0]} \mathrm{is} \mathrm{immobilized} \mathrm{onto} \mathrm{nano-}$ $\mathrm{ZnO} / \mathrm{ITO}$ film $\left(0.25 \mathrm{~cm}^{2}\right)$ via physisorption and kept overnight for drying. The higher activity of $\mathrm{ChOx} /$ nano-ZnO/ITO bioelectrode obtained at $p \mathrm{H} 7.0$ reveals that $\mathrm{ChOx} /$ nano$\mathrm{ZnO} / \mathrm{ITO}$ bioelectrode is more active at $p \mathrm{H} \mathrm{7.0.}$

$\mathrm{X}$-ray diffraction (XRD) [Cu $K \alpha$ radiation (Rigaku)], atomic force microscopy (AFM) (Veeco DICP2), and Fourier-transform infrared (FTIR) (Perkin-Elmer, Model 2000) studies have been conducted for characterization of nano-ZnO/ITO electrode and $\mathrm{ChOx} /$ nano-ZnO/ITO bioelectrode. Electrochemical studies are carried out on an Autolab potentiostat/galvanostat in PB saline (PBS) $(50 \mathrm{mM}, p \mathrm{H} 7.0$, $0.9 \% \mathrm{NaCl})$ containing $5 \mathrm{mM}\left[\mathrm{Fe}(\mathrm{CN})_{6}\right]^{3-/ 4-}$.

Figure 1(a) exhibits XRD pattern of nano-ZnO film revealing growth of oriented nanocrystallites (estimated as $10 \mathrm{~nm}$ using Scherer equation) in preferred (002) reflection plane at $34.5^{\circ}$ indicating growth along $c$-axis normal to nano- $\mathrm{ZnO}$ film due to presence of stress in $\mathrm{ZnO}$ film arising due to embedded oxygen at interstitial sites in nano- $\mathrm{ZnO}$ film at $500{ }^{\circ} \mathrm{C}$. $^{4}$

FTIR [Fig. 1(b)] of nano-ZnO film (curve a) exhibits weak bands at 3350 and $1594 \mathrm{~cm}^{-1}$ corresponding to $\mathrm{O}-\mathrm{H}$ stretching due to physically adsorbed water on nano- $\mathrm{ZnO}$ film surface. $520 \mathrm{~cm}^{-1}$ band (curve a) arises due to oxygen deficiency and/or oxygen vacancy defect complex in $\mathrm{ZnO} .^{12,13}$ On immobilization of $\mathrm{ChOx}$ onto sol-gel derived nano- $\mathrm{ZnO}, 520 \mathrm{~cm}^{-1}$ peak shifts to $540 \mathrm{~cm}^{-1}$ due to electrostatic interactions between nano- $\mathrm{ZnO}$ and $\mathrm{ChOx}$. FTIR spectra of $\mathrm{ChOx} /$ nano-ZnO/ITO (curve b) exhibits bands at $3250 \mathrm{~cm}^{-1}$ (corresponding to $\mathrm{N}-\mathrm{H}$ stretching in amide II), $1590 \mathrm{~cm}^{-1}$ (corresponding to $\mathrm{C}-\mathrm{N}$ stretching and $\mathrm{N}-\mathrm{H}$ bending modes of amide I bands), and $1000 \mathrm{~cm}^{-1}$ (assigned to $\mathrm{C}-\mathrm{O}$ stretching) due to amide bands in protein revealing immobilization of $\mathrm{ChOx}$ onto nano- $\mathrm{ZnO}$ film via electrostatic interactions. 

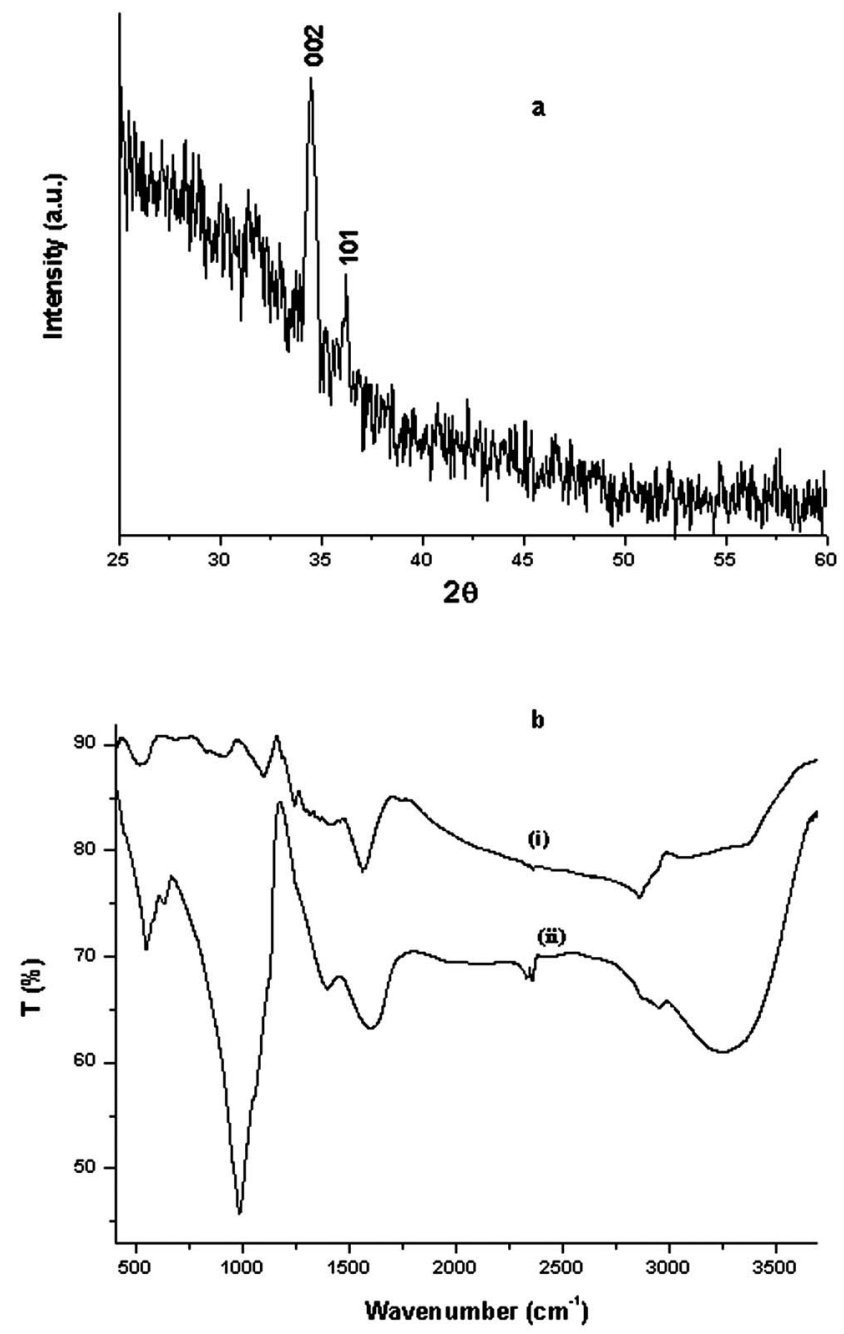

FIG. 1. (a) XRD pattern of sol-gel derived $\mathrm{ZnO}$ film. (b) FTIR spectra of nano-ZnO/ITO electrode (i) and ChOx/nano-ZnO/ITO bioelectrode (ii).

AFM images (supplementary data ${ }^{14}$ ) exhibit granular nanoporous morphology of nano-ZnO/ITO electrode with surface roughness of $127 \mathrm{~nm}$. However, the roughness decreases to $80 \mathrm{~nm}$ after ChOx immobilization onto nano- $\mathrm{ZnO} /$ ITO electrode revealing that nano- $\mathrm{ZnO}$ film provides a biocompatible environment for ChOx. Furthermore, bearing ratio plots of nano-ZnO/ITO electrode (supplementary data $^{14}$ ) and ChOx/nano-ZnO/ITO bioelectrode (supplementary data ${ }^{14}$ ) show uniform surface topologies.

The results of $C V$ studies [Fig. 1(a)] reveal that magnitude of current $(0.21 \mathrm{~mA})$ is enhanced as (curve ii) compared to that of bare ITO (curve i) revealing that nano- $\mathrm{ZnO}$ results in enhanced electron transport due to arrangement of $\mathrm{ZnO}$ molecules resulting in increased electrocatalytic surface area. The magnitude of current response further increases to 0.28 $\mathrm{mA}$ for $\mathrm{ChOx} / \mathrm{nano}-\mathrm{ZnO} / \mathrm{ITO}$ bioelectrode revealing that nano-ZnO/ITO electrode provides three-dimensional platform for $\mathrm{ChOx}$, resulting in enhanced electron communication between ChOx and electrode. Results of differential pulse voltammetric studies reveal similar behavior (supplementary data ${ }^{14}$ ).

The results of $C V$ studies [Fig. 2(b)] of ChOx/nano- $\mathrm{ZnO} /$ ITO bioelectrode conducted as a function of scan rate (10$100 \mathrm{mV} / \mathrm{s})$ reveal that peak-to-peak separation potential $(\Delta E$, $\sim 0.16 \mathrm{~V}$ ) increases with increasing scan rate (inset), indi-
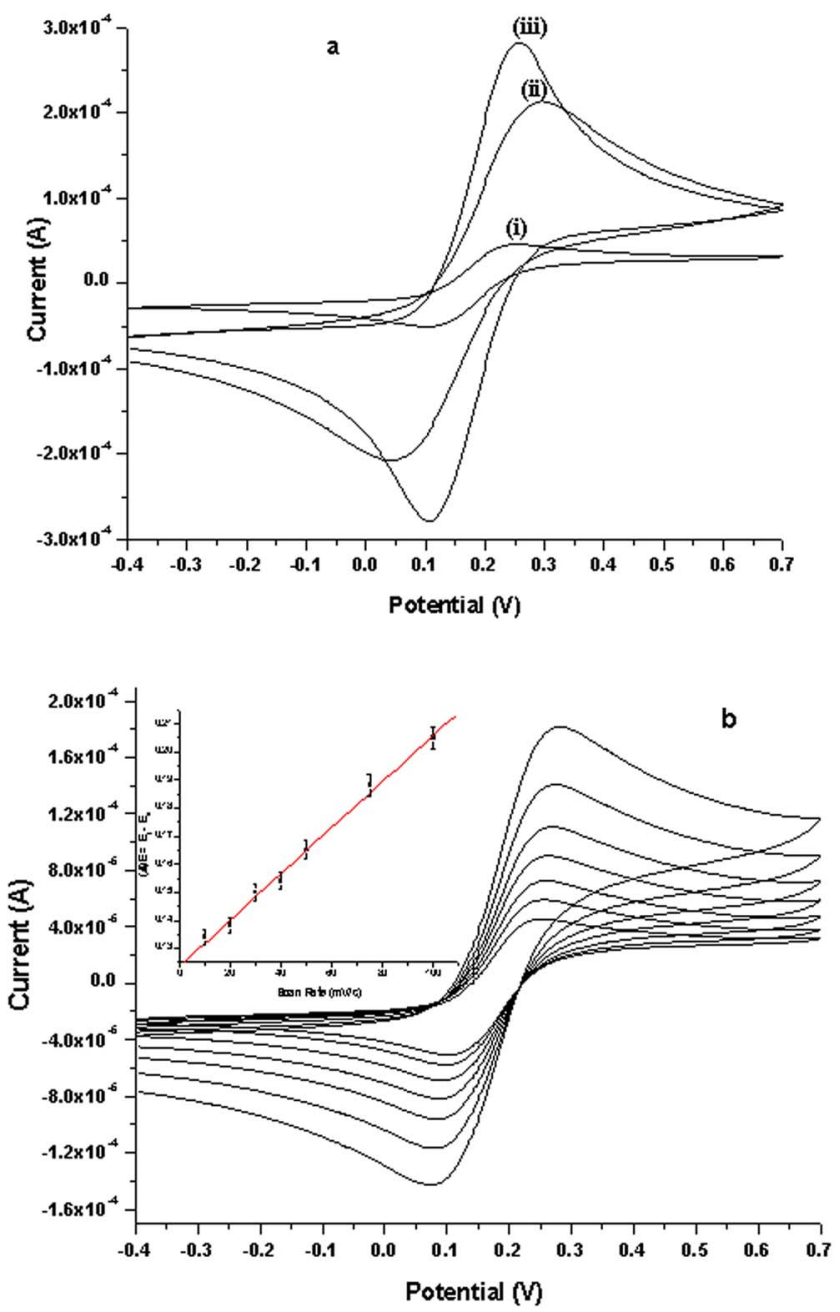

FIG. 2. (Color online) (a) Cyclic voltammogram of ITO electrode (i) nano$\mathrm{ZnO} / \mathrm{ITO}$ electrode (ii) and ChOx/nano-ZnO/ITO bioelectrode (iii). (b) $\mathrm{Cy}$ clic voltammogram of ChOx/nano-ZnO/ITO bioelectrode at different scan rates $(10-100 \mathrm{mV} / \mathrm{s})$. Inset is plot of potential difference vs scan rate.

cating uniform facile charge transfer kinetics and follows

$\Delta E(V)(\mathrm{ChOx} /$ nano $-\mathrm{ZnO} / \mathrm{ITO}$ bioelectrode $)$

$$
\begin{aligned}
& =0.12 \mathrm{~V}+0.81 \times 10^{-6}(\mathrm{~s}) \times \mathrm{scan} \mathrm{rate}(\mathrm{mV} / \mathrm{s}) \text { with } R^{2} \\
& =0.994 \ldots
\end{aligned}
$$

The surface concentration of ionic species onto ChOx/nano$\mathrm{ZnO} / \mathrm{ITO}$ bioelectrode has been found as 1.86 $\times 10^{-8} \mathrm{~mol} \mathrm{~cm}^{-2}$ using $^{15}$

$$
i_{p}=0.227 n F A C_{0}^{*} k^{0} \exp \left[\frac{-\alpha n_{a} F}{\mathrm{RT}}\left(E_{p}-E_{0}^{\prime}\right)\right] \ldots,
$$

where $i_{p}$ is the anodic peak current, $n$ is the number of electrons transferred (1), $F$ is Faraday constant (96 $\left.485.34 \mathrm{C} \mathrm{mol}^{-1}\right), A$ is surface area $\left(0.25 \mathrm{~cm}^{2}\right), R$ is gas constant $\left(8.314 \mathrm{~J} \mathrm{~mol}^{-1} \mathrm{~K}^{-1}\right), C_{0}^{*}$ is surface concentration of ionic species onto the film surface $\left(\mathrm{mol} / \mathrm{cm}^{-3}\right), E_{p}$ is peak potential, and $E_{0}^{\prime}$ is formal potential. $-\alpha n_{a} F / \mathrm{RT}$ and $k^{0}$ (rate constant) corresponds to the slope and intercept of $\ln \left(i_{p}\right)$ versus $E_{p}-E_{0}^{\prime}$ curve at a given scan rate.

Electrochemical response studies [Fig. 3(a)] of ChOx/ nano- $\mathrm{ZnO} / \mathrm{ITO}$ bioelectrode conducted as a function of cholesterol concentration reveal that current response increases 

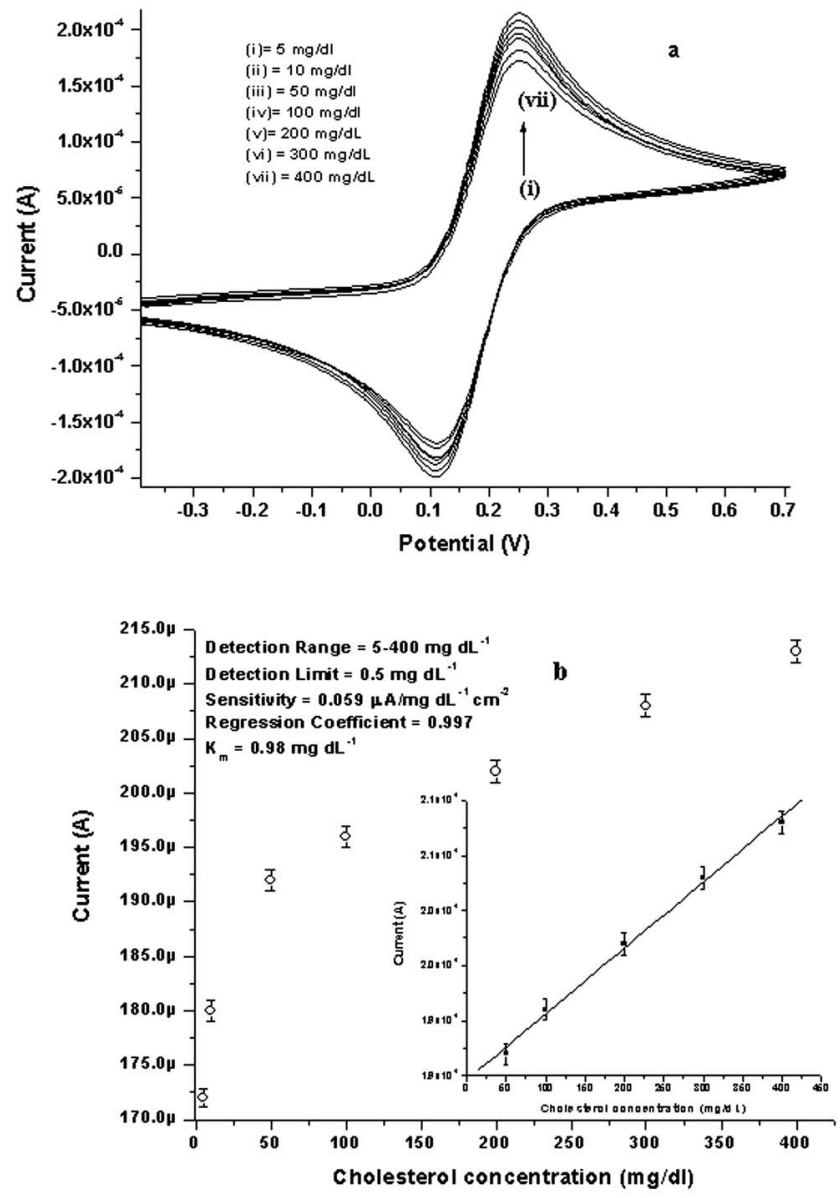

FIG. 3. (a) Electrochemical response of $\mathrm{ChOx} /$ nano-ZnO/ITO bioelectrode with respect to cholesterol concentration $(5-400 \mathrm{mg} / \mathrm{dl})$ at the scan rate of $20 \mathrm{mV} \mathrm{s}^{-1}$. (b) The variation in current as a function of cholesterol concentration. Inset is linearity curve between magnitude of current vs cholesterol concentration.

with successive addition of cholesterol. This may perhaps be due to well aligned and closed packed network of nano- $\mathrm{ZnO}$ that acts as good accepter of electron generated during reoxidation of $\mathrm{ChOx}$ and transferred to electrode via $\mathrm{Fe}(\mathrm{III}) /$ $\mathrm{Fe}(\mathrm{IV})$ conversion resulting in increased electrochemical current response.

The ChOx/nano-ZnO/ITO bioelectrode exhibits detection range of $5-400 \mathrm{mg} / \mathrm{dl}$, detection limit of $0.5 \mathrm{mg} / \mathrm{dl}$, response time of $10 \mathrm{~s}$, and reproducibility of 20 times. However, good linearity is obtained in $50-400 \mathrm{mg} / \mathrm{dl}$ range with linear regression coefficient $\left(R^{2}\right)$ as 0.997 [Fig. 3(b)]. The results of triplicate sets reveal reproducibility within $1 \%$. The magnitude of current response as a function of cholesterol concentration [50-400 mg/dl, inset of Fig. 3(a)] follows

\section{$I_{p}(A)(\mathrm{ChOx} /$ nano $-\mathrm{ZnO} / \mathrm{ITO})$}

$$
\begin{aligned}
& =189 \times 10^{-6}(A)+0.059 \times 10^{-6} \mathrm{~A} \mathrm{dl} / \mathrm{mg} \\
& \times \text { cholesterol concentration }(\mathrm{mg} / \mathrm{dl}) \ldots
\end{aligned}
$$

The Michaelis-Menten constant $\left(K_{m}\right)$ value obtained as $0.98 \mathrm{mg} / \mathrm{dl}$ using Lineweaver-Burke plot is lower than that of other metal oxide based cholesterol biosensors (supplementary data $\left.{ }^{14}\right){ }^{2,3,10,14,16,17}$ The observed higher affinity of ChOx/nano-ZnO/ITO bioelectrode can be attributed to favor- able conformation of $\mathrm{ChOx}$ and higher loading onto nano$\mathrm{ZnO}$ film. ${ }^{3}$ It appears that NS-ZnO/ITO film results in higher activity of immobilized ChOx molecules due to their improved conformation and orientation leading to their enhanced interaction (lower $K_{m}$ ) with substrate molecules resulting in low detection limit of the ChOx/NS-ZnO/ITO electrode.

The sensitivity of this ChOx/nano-Zno/ITO bioelectrode is obtained as $0.059 \mu \mathrm{A} / \mathrm{mg} \mathrm{dl}^{-1} \mathrm{~cm}^{-2}$ with linear regression coefficient $\left(R^{2}\right)$ as 0.997 . The selectivity of ChOx/nano$\mathrm{ZnO} / \mathrm{ITO}$ bioelectrode determined by measuring response current on addition of normal concentration of interferents such as ascorbic acid (AA), uric acid (UA), glucose (G), lactic acid (LA), sodium pyruvate, and urea (1) at normal concentration in blood samples [inset of Fig. 3(a)] indicates maximum interference of $4.6 \%$. The storage stability of ChOx/nano-ZnO/ITO bioelectrode determined by measuring change in current response at regular interval of 1 week exhibits $80 \%$ response after about 3 months when stored at $4{ }^{\circ} \mathrm{C}$.

The ChOx/nano-ZnO/ITO cholesterol biosensor has been found to have improved detection range $(5-400 \mathrm{mg} / \mathrm{dl})$, low detection limit $(0.5 \mathrm{mg} / \mathrm{dl})$, linear regression at 0.994 , response time (10 s), and shelf-life ( 3 months). The low $K_{m}$ value $(0.98 \mathrm{mg} / \mathrm{dl})$ indicates high affinity of ChOx/nano$\mathrm{ZnO} / \mathrm{ITO}$ bioelectrode to cholesterol. Efforts should be made to improve sensitivity of this electrode by controlling shape and size of nano- $\mathrm{ZnO}$ and to utilize this electrode for estimation of triglycerides and lipoproteins etc.

We thank Director, NPL, India for facilities. P.R.S., A.A.A., and A.K. thank CSIR, India for award of Senior Research Associate (SRA).

${ }^{1}$ P. R. Solanki, A. Kaushik, A. A. Ansari, G. Sumana, and B. D. Malhotra, Appl. Phys. Lett. 93, 163903 (2008).

${ }^{2}$ S. P. Singh, S. K. Arya, P. Pandey, B. D. Malhotra, S. Saha, K. Sreenivas, and V. Gupta, Appl. Phys. Lett. 91, 063901 (2007).

${ }^{3}$ A. A. Ansari, A. Kaushik, P. R. Solanki, and B. D. Malhotra, Electrochem. Commun. 10, 1246 (2008).

${ }^{4}$ S. Krishnamoorthy, T. Bei, E. Zoumakis, G. P. Chrousos, and A. A. Iliadis, Biosens. Bioelectron. 22, 707 (2006).

${ }^{5}$ J. X. Wang, X. W. Sun, A. Wei, Y. Lei, X. P. Cai, C. M. Li and Z. L. Dong, Appl. Phys. Lett. 88, 233106 (2006).

${ }^{6}$ X. Zhu, I. Yuri, X. Gan, I. Suzuki, and G. Li, Biosens. Bioelectron. 22, 1600 (2007).

${ }^{7}$ Z. Yan, Z. Song, W. Liu, H. Ren, N. Gu, X. Zhou, L. Zhang, Y. Wang, S. Feng, L. Lai, and J. Chen, Appl. Surf. Sci. 253, 9372 (2007).

${ }^{8}$ A. Wei, X. W. Sun, J. X. Wang, Y. Lei, X. P. Cai, C. M. Li, Z. L. Dong, and W. Huang, Appl. Phys. Lett. 89, 123902 (2006).

${ }^{9}$ E. A. Meulenkamp, J. Phys. Chem. B 102, 5566 (1998).

${ }^{10}$ R. Khan, A. Kaushik, P. R. Solanki, A. A. Ansari, M. K. Pandey, and B. D. Malhotra, Anal. Chim. Acta 616, 207 (2008).

${ }^{11}$ A. A. Ansari, P. R. Solanki, and B. D. Malhotra, Appl. Phys. Lett. 92, 263901 (2008).

${ }^{12}$ J. Zheng, R. Ozisik, and R. W. Siegel, Polymer 46, 10873 (2005).

${ }^{13}$ G. Xiong, U. Pal, J.G. Serrano, K.B. Ucer, R.T. Williams, Phys. Status Solidi C 3, 3577 (2006).

${ }^{14}$ See EPAPS Document No. E-APPLAB-94-075913 for results of AFM, DPV studies and Table I. For more information on EPAPS, see http:// www.aip.org/pubservs/epaps.html.

${ }^{15}$ N. Prabhakar, K. Arora, S. P. Singh, M. K. Pandey, H. Singh, and B. D. Malhotra, Anal. Chim. Acta 589, 6 (2007).

${ }^{16}$ G. K. Kouassi, J. Irudayaraj, and G. McCarty, J. Nanobiotech. 3, 1 (2005).

${ }^{17}$ S. Aravamudhan, A. Kumar, S. Mohapatra, and S. Bhansali, Biosens. Bioelectron. 22, 2289 (2007) 